\title{
FAMÍLIAS FELIZES E SAUDÁVEIS! LIVROS DIDÁTICOS DE MATEMÁTICA E A PRODUÇÃO DE SUJEITOS
}

\author{
HAPPY AND HEALTHY FAMILIES! MATHEMATICS TEXTBOOKS AND THE MAKING OF SUBJECTS
}

¡FAMILIAS FELICES Y SANAS! LIBROS DE TEXTO DE MATEMÁTICAS Y LA PRODUCCIÓN DE MATERIA

\author{
CORADETTI, Camila Aparecida Lopes Manoel ${ }^{1}$ \\ SILVA, Marcio Antonio da ${ }^{2}$
}

\section{RESUMO}

Este artigo tem o objetivo de analisar as representações de famílias contidas em atividades de matemática financeiras, dos livros didáticos de matemática do Ensino Médio aprovados no PNLD de 2015, especificamente para descrever a produção de sujeitos. Para a análise utilizamos as contribuições de Stuart Hall sobre representação, além de algumas ferramentas foucaultianas, como a análise do discurso e a constituição do sujeito. Concluímos que há ligação entre as ideias de "boas" práticas econômicas e "saúde" financeira. Há uma narrativa que sugere vida "saudável" a quem seguir à risca as orientações contidas nesses livros. Cada membro da família é um empreendedor de si e responsável pelo sucesso ou fracasso dessa empresa-família, cuja matériaprima é o capital humano. As representações também relacionam a ideia de sucesso econômico com a obtenção de felicidade. Essas atividades subjetivam os alunos, os quais são educados para serem inseridos em uma sociedade governada por políticas neoliberais.

Palavras-chave: Currículo. Livros Didáticos. Matemática Financeira. Representação. Análise do Discurso.

\section{ABSTRACT}

In this article, we aim to analyze representations of families in Brazilian high school mathematics textbooks, to describe the making of subjects. For that, we have analyzed images contained in financial mathematics activities, present in the books approved by the Brazilian National Textbook Program, in 2015. For that exercise of thought we have used Stuart Hall's contributions about representation, as well Foucauldian tools, such as discourse analysis and the constitution of the subject. Through the analysis, we conclude that there are regularities in the representations, in which we have founded a connection between the ideas of "good" economic practices and financial "health". What these representations seem to suggest is that, if the instructions contained in the images, a financial "healthy" life will be achieved. This representation goes through understanding family as company that it produces human capital, constituting each member as a self-entrepreneur who is responsible for the success or failure of this company-family. These representations also seem linked to the idea of economic success for happiness. Those activities subjective students, which are educated to be inserted in a society governed by neoliberal policies.

Keywords: Curriculum. Textbooks. Financial Mathematics. Representation. Discourse Analysis.

\section{RESUMEN}

En este artículo tenemos el objetivo de analizar las representaciones de las familias contenidas en los libros de texto de matemáticas de la high School secundaria, para describir la producción del sujeto. Para lograr este objetivo, analizamos imágenes contenidas en las actividades de matemáticas financieras, presentes en los libros aprobados por el PNLD para 2015. Para este ejercicio de pensamiento fueron usadas contribuciones de Stuart Hall sobre la representación, así como algunas herramientas foucaultianas como Análisis del Discurso y la Constitución del sujeto. A través de los análisis, concluimos que hay regularidades en las representaciones contenidas en estos libros, en el que vemos una conexión entre las ideas de "buenas prácticas" y "salud". Lo que estas representaciones parecen sugerir es que, si las instrucciones contienen en las imágenes, se logrará una vida "sana". Esta representación va através de la comprensión de la familia como un productor de capital humano; cada miembro es un empresario y responsable del éxito o fracaso de esta empresa familiar. Las representaciones están ligadas también a la idea del éxito económico para alcanzar la felicidad. Estos actividades subjetivam los estudiantes, educados en una sociedad gobernada por las políticas neoliberales.

Palabras clave: Plan de estúdios. Libros de texto. Matemáticas financeiras. Representación. Análisis del discurso.

\footnotetext{
1 Universidade Federal do Mato Grosso do Sul - UFMS - Campo Grande - Mato Grosso do Sul - Brasil

2 Universidade Federal do Mato Grosso do Sul - UFMS - Campo Grande - Mato Grosso do Sul - Brasil
} 


\section{INTRODUÇÃO}

Este artigo traz alguns resultados de uma pesquisa de mestrado (CORADETTI, 2017), realizada pela primeira autora e orientada pelo segundo autor. Nessa pesquisa, foram analisados os discursos que permeavam os livros didáticos de matemática, enfocando o tema "matemática financeira". Entre os resultados evidenciou-se a prevalência de uma abordagem acerca da importância da matemática financeira na vida das pessoas, a qual conduzia a normas sobre como produzir uma família feliz, uma felicidade que está diretamente relacionada à adequada gestão do dinheiro, por intermédio de uma constituição familiar similar à constituição de uma empresa bem administrada e eficaz, constituída por sujeitos economicamente úteis e empreendedores (CORADETTI; SILVA, 2017). Especificamente este artigo, analisamos as representações de famílias contidas em atividades de matemática financeiras, em livros didáticos de matemática do Ensino Médio aprovados pelo Programa Nacional do Livro e do Material Didático - PNLD de 2015, para descrever a produção de sujeitos.

O tema "família" não é inédito em pesquisa, sobretudo na área dos estudos culturais, mas é pouco investigado e analisado na educação matemática. Nossa investigação transita em intersecções das áreas dos estudos culturais e da educação matemática, não estabelecendo fronteiras fixas que delimitam e promovem processos de in(ex)clusão de temáticas de pesquisa (SILVA; MIARKA, 2017). O interesse por identificar os tipos de sujeitos que os livros didáticos de matemática tentam produzir é um foco relativamente recente de pesquisa do nosso grupo (SILVA, 2016), Grupo de Pesquisa Currículo e Educação Matemática - GPCEM.

O GPCEM também tem tentado problematizar³, criar modos de observar como as enunciações sobre a matemática financeira, presentes nos livros didático de matemática do Ensino Médio, constituem-se objetos para o pensamento. Trata-se de um exercício de observação de como as representações da matemática financeira vão além da transmissão de conhecimento científico, mas também produzem uma moralidade republicana (TRÖHLER; POPKEWITZ; LABAREE, 2011) que contribui para a constituição de sujeitos ou para a formação de alunos.

O contexto político que atravessa as propostas dos livros didáticos de matemática que foram analisadas na investigação é o contexto de políticas neoliberais na educação. O neoliberalismo é uma forma de governo que emergiu em meados do século XX, para sermos mais específicos. Um marco da emergência do neoliberalismo foi a publicação da obra de Friedrich Hayek, em 1944, que preconiza uma doutrina econômica, restringindo à intervenção estatal na economia e o fundamentalismo de livremercado (HÖFLING, 2001).

Anderson (1995) aponta que o neoliberalismo possui algumas diferenças do liberalismo clássico. Para Veiga-Neto (2013, p. 38), uma diferença é que, no liberalismo, a ideia de liberdade de

\footnotetext{
${ }^{3}$ Cf. Foucault (2004, p. 242), "problematização não quer dizer a representação de um objeto preexistente, nem tampouco a criação pelo discurso de um objeto que não existe. É o conjunto das práticas discursivas ou não discursivas que faz alguma coisa entrar no jogo do verdadeiro e do falso e o constitui como objeto para o pensamento (seja sob a forma da reflexão moral, do conhecimento científico, da análise política etc.)".
} 
mercado era vista "como algo natural e espontâneo". Já, no neoliberalismo, essa liberdade "deve ser continuamente produzida e exercida sob a forma de competição".

Nessa racionalidade, o estado se desvincula de algumas obrigações, retirando seu papel intervencionista e passando essa responsabilidade para o sujeito ou grandes corporações, em que o estado é "um conjunto de instituições já estabelecidas, de todo um conjunto de realidades já dadas" (FOUCAULT, 2008b, p. 385). Nesse sentido, considera-se plausível pensar em uma formação para as pessoas que atuam nesse tipo de sociedade, sendo esse o papel fundamental do currículo e das escolas.

\section{CONSIDERAÇÕES TEÓRICO-METODOLÓGICO}

Inspirados por Hall (2016), e também, pelas concepções com as quais seguimos, consideramos $\mathrm{O}$ ato de definir "cultura" uma tarefa impossível e desnecessária. O que buscamos, a partir daqui, são aproximações de ideias sobre "cultura" para potencializar a discussão sobre currículos de matemática na contemporaneidade.

Em consonância com Hall (2016, p. 20), concebemos cultura como algo que excede um conjunto de práticas, uma vez que

[...] a cultura diz respeito à produção e ao intercâmbio de sentidos - o "compartilhamento de significados" - entre os membros de um grupo ou sociedade. Afirmar que dois indivíduos pertencem à mesma cultura equivale a dizer que eles interpretam o mundo de maneira semelhante e podem expressar seus pensamentos e sentimentos de forma que um compreenda o outro.

Entendemos que os participantes de uma cultura dão sentidos aos indivíduos, aos objetos e aos acontecimentos. Sentidos cultivam a noção de identidade, regulando e organizando nossa conduta, e que, de acordo com Hall (2016, p. 22), "[...] auxiliam no estabelecimento de normas e convenções segundo as quais a vida em sociedade é ordenada e administrada". Dessa maneira, estando inseridos em uma cultura de políticas neoliberais para o currículo de matemática, podemos pensar que este estabelece normas e convenções indentárias, com base nessa cultura, do tipo de pessoa que a escola deve formar.

Esses sentidos, compartilhados por uma determinada cultura, são manifestados por meio da linguagem, seja falada ou não. A linguagem cria os objetos de que falam (SILVA, 2015), ou seja, criam modos de representar algo, tendo em vista que "[...] não se reduz ao que são, mas sim ao que fazem, a suas funções" (HALL, 2016, p. 24). É por meio da linguagem que os significados são compartilhados e, quando produzido e intercambiados, produzem sentidos.

Hall (2016) menciona que a linguagem fornece um modelo de funcionamento da cultura e da representação. $O$ autor divide a linguagem em duas abordagens: a semiótica e a discursiva. Neste trabalho, estamos preocupados com os efeitos e consequências da representação, por isso seguimos 
uma abordagem discursiva. Em outras palavras, estamos interessados em "[...] como o conhecimento elaborado por determinado discurso se relaciona com o poder, regula condutas, inventa ou constrói identidades e subjetividades e define o modo pelo qual certos objetos são representados, concebidos, experimentados e analisados" (HALL, 2016, p. 27). Essas intenções se articulam com as ideias de pedagogias culturais, de como os "[...] artefatos da cultura são pedagógicos ao nos ensinarem modos de ser e a partir da regulação de nossas condutas" (ANDRADE, 2016, p. 31).

Partindo do pressuposto de que a representação está alinhada à concepção de pedagogia cultural, temos que a representação funciona como uma língua específica, com regras próprias, representando ou dando sentido "aquilo que queremos dizer e para expressar ou transmitir um pensamento, um conceito, uma ideia, um sentimento" (HALL, 2016, p. 24). Decorrente dessa premissa, podemos pensar que o currículo apresentado aos professores e alunos na forma de livros de matemática prevê os conceitos matemáticos e como ensiná-los, mas, também, e sobretudo, prediz formas de representar conhecimentos não-conceituais, contribuindo para a produção de sujeitos alinhados ao modo de ser e de estar no mundo neoliberal moderno.

Nessa perspectiva, o currículo pode ser considerado uma prática cultural, como uma "produção social, por meio da linguagem, ou seja, a linguagem, ao invés de representar o mundo, o constrói" (LOPES; MACEDO, 2011, p. 38). Consideramos a linguagem como "discurso" e o discurso como um sistema de representação, como um ato de poder.

Nesse sentido, servimo-nos da análise do discurso, ferramenta escolhida na "caixa" foucaultiana, para discutir, neste artigo, as subjetividades que produzidas pelos currículos de matemática, as quais, por sua vez, também produzem sujeitos por meio das representações de famílias.

Diante desse pensamento investigativo, é importante enfatizar a articulação existente entre análise do discurso, na perspectiva foucaultiana, e a constituição dos sujeitos. Em uma entrevista realizada nos últimos anos de sua vida, Foucault (1995, p. 231) fez questão de explicitar que o seu grande objetivo foi: "criar uma história dos diferentes modos pelos quais, em nossa cultura, os seres humanos tornaram-se sujeitos".

Os sujeitos são constituídos no e pelo discurso, ou seja, o sujeito é sujeito no sentido etimológico da palavra, "[...] é um lugar vazio - que ao ser ocupado reflete e é refletido pelas relações de poder que organizam as possibilidades discursivas operadas nesse espaço" (MONTEIRO; MENDES; MASCIA, 2010, p. 54). Nesse sentido, analisar as instruções contidas em atividades de matemática financeira, nos livros didáticos do Ensino Médio, é descrever possibilidades discursivas que fazem com que os alunos se tornem sujeitos dos discursos produzidos por esses livros. Em síntese, as análises são exercícios para descrever como a matemática financeira opera instâncias para moldar e instruir a conduta de alunos, criando modos de representação.

Para esse trabalho, buscamos analisar discursividades que se articulam na superfície do conteúdo matemático nos livros didáticos. Para esse movimento, apropriamo-nos de alguns conceitos foucaultianos, a fim de buscar relações de poder que agem para a formação de sujeitos pelo currículo 
de matemática financeira. Trata-se, pois, de buscar enunciados constitutivos de uma realidade que produz, por meio de saberes, discursos no campo da educação matemática.

Ressaltamos que esses discursos, presentes nos livros didáticos, instruem alunos inseridos em uma instituição de ensino com marcas neoliberais, marcas estas que tomam a escola não como um "[...] lugar onde se ensinam e se aprendem ideologias, ela, bem mais que isso, passa a ser entendida como uma instituição encarregada de fabricar novas subjetividades" (VEIGA-NETO, 2013, p. 38). São subjetividades geradas por processos criados em nossa sociedade, em nossa cultura, fazendo do homem um sujeito preso a uma identidade que the é atribuída como sua.

Segundo Larrosa (2011, p. 53), "na perspectiva de Foucault, a questão do 'governo' está, já desde o princípio, fortemente relacionada com a questão do 'autogoverno', estando [...] claramente relacionada com o tema da 'subjetividade"'. O currículo de matemática entra no jogo do verdadeiro e do falso, endereçando instruções econômicas alinhadas ao ideal neoliberal, por intermédio de atividades de matemática financeira. Desse modo, a escola torna-se um lugar que fabrica sujeitos governáveis, produzidos em uma racionalidade neoliberal. Por sujeitos governáveis, entendemos aqueles que podem ser conduzidos - por si ou por outros - por ações estabelecidas em relações de poder (VEIGANETO; LOPES, 2010) que se dão na sutileza de discursividades de um currículo de matemática, naturalizadas e, por isso, problematizáveis em seus jogos do verdadeiro e do falso.

\section{ALGUNS PROCEDIMENTOS}

Analisamos os seis livros de Matemática do Ensino Médio, aprovados pelo Programa Nacional do Livro e do Material Didático - PNLD de 2015, que continham o tema "matemática financeira": "Matemática Paiva" (PAIVA, 2013, v.1); "Conexões com a Matemática" (LEONARDO, 2013, v.3); "Matemática - Contextos e Aplicações" (DANTE, 2013, v.3); "Matemática, Ciência e Aplicações" (IEZZI et al., 2010, v.3); "Matemática Ensino Médio" (SMOLE; DINIZ, 2013, v.3) e "Novo Olhar - Matemática (SOUZA, 2013, v.2). No total, foram analisadas cerca de 115 páginas.

Nossos olhares foram direcionados para as discursividades que formam enunciações no material analisado, ou seja, frases presentes em atividades, no material direcionado para o professor e, também, nas figuras que ilustram o material didático.

Para as análises das imagens, buscamos as contribuições de Collange, Almeida e Amorim (2014), inspirando-nos, principalmente, na parte que explicita a metodologia de análise por meio da

[...] submissão da imagem à sua descrição e transformação em texto escrito, tratando-a, analiticamente, de forma equivalente à palavra escrita, à narrativa, à expressão do conceito e/ou às teorias das concepções mentais, sociais muito presentes nos estudos de aprendizagem em ensino de ciências". (COLLANGE; ALMEIDA; AMORIM, 2014, p.826). 
Inspirados nesses autores, realizamos uma análise descritiva sobre a linguagem e, consequentemente, a produção cultural e aos modos de representação das imagens de famílias presentes nesses livros didáticos de matemática do Ensino Médio. Quando os materiais didáticos, a partir das imagens, cingem-se à matemática financeira, fazem-no como uma prática de produção cultural, criando sentidos híbridos, heterogêneos e retirados de diferentes contextos (GARCÍA CANCLINI, 2008; SILVA, 2012).

\section{A REPRESENTAÇÃO DE FAMÍLIAS E A MATEMÁTICA FINANCEIRA DOS LIVROS DIDÁTICOS}

Como já mencionamos anteriormente sobre o neoliberalismo, gostaríamos de retomar com a racionalidade neoliberal para criar potência para a análise das imagens e excertos dos livros didáticos de matemática do ensino médio. O intuito dessa retomada é pela intensidade com a qual essas ideias atravessam as imagens analisadas, contribuindo para a formação de um tipo de identidade alinhada a esses ideais, como veremos nos excertos a seguir.

Figura 1 - Modos de representação de Famílias nos livros didáticos

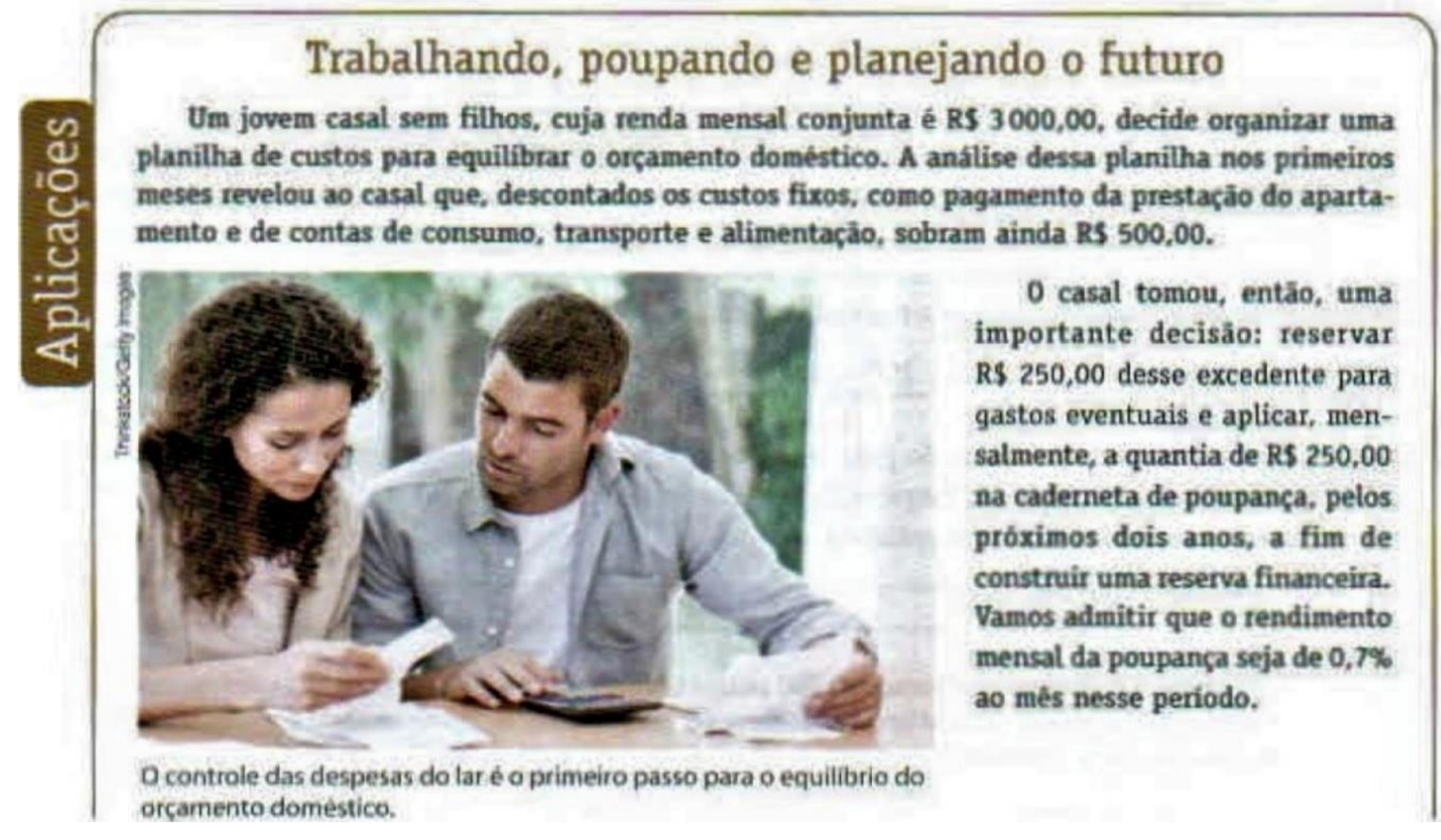

Fonte: lezzi et al. (2013, v. 3, p. 163).

O texto que acompanha a Figura 1 recebe o título "Trabalhando, poupando e planejando o futuro" que ressalta "uma importante decisão" tomada por um casal - a de poupar uma quantia mensal para construir uma reserva financeira. 
A Figura 1 apresenta o modelo familiar "tradicional ocidental" sugerido pela imagem de um casal, sem filhos. Muitos esforços têm sido feitos no sentido de normalizar uma pluralidade de formas de se constituir uma família, na sociedade atual, até mesmo em outras áreas do conhecimento, como em Fiuza e Poli (2015, p. 151), no qual os autores concebem a família na "[...] condição de núcleo de peculiaridade dinâmica, pode assumir variados contornos". No entanto, nos livros analisados nesse trabalho, apresentam formas fixas do que se considera uma família. O que queremos, com essa análise, é explicitar que, juntamente com uma suposta objetividade contida em um problema de matemática adequadamente contextualizado e com a louvável função de ensinar taxa de juros compostos, a alquimia da matemática escolar (POPKEWITZ, T. S., 2004) também propõe como ser família, qual a forma 'certa' ou 'aceitável' de viver em sociedade, entre outras instruções aparentemente não-matemáticas.

O texto informativo da Figura 1 também reforça, um exemplo de família que faz planejamento familiar, o que nos encaminha para a ideia de que essa tarefa doutrina sobre a produção de sujeitos responsáveis, os quais contribuirão para o seu próprio sucesso, para o sucesso da sua família e para o da economia de estado. Essa análise é feita com base no que Foucault (2008a) mencionou, que no neoliberalismo podem existir relações mercantis e não-mercantis; nesse caso, a relação entre o modelo de família ocidental moderna e a matemática financeira dos livros didáticos de matemática do Ensino Médio podem se estabelecer por relações não-mercantis.

As relações não-mercantis são reconhecidas como fenômenos sociais que influenciam no mercado, ou seja, as influências sociais que têm como foco a população, e que incidem sobre as relações econômicas. O incentivo ao modelo de família ocidental moderna pode provocar essas relações não-mercantis, que, por sua vez, podem ser reprodutoras de um certo tipo de capital, não necessariamente bens físicos, mas sim um capital humano (VALERO, 2017).

Com base nas ideias mencionadas anteriormente, inferimos que o modelo de família ocidental moderna pode ser visto também como uma empresa, sendo composta por seres humanos que buscam administrar suas ações, decisões e produzir bens e, consequentemente, capital.

[...] a própria vida do indivíduo - com, por exemplo, sua relação com a sua propriedade privada, sua relação com a sua família, com o seu casamento, com os seus seguros, com a sua aposentadoria - tem de fazer dele como que uma espécie de empresa permanente e de empresa múltipla. (FOUCAULT, 2008a, p. 331).

Desse modo, nessa pesquisa encontramos evidências do quanto o modelo de família se aproxima de uma empresa, conforme já mencionado anteriormente, corroborado por Foucault (2008a, p. 336): "[...] trata-se de fazer do casal uma unidade de produção ao mesmo título que a firma clássica". Além disso, observamos outra característica semelhante ao que Foucault (2008a) denominou "um contrato a longo prazo" - o casamento - uma relação entre homem e mulher que pode ser considerada como facilitadora de algumas transações, de trocas entre eles, o trabalho em conjunto, a tomada de 
decisão, o reconhecimento das opções mais vantajosas e, também, aquisição de bens físicos e não físicos, mas uma maneira de manter um determinado tipo de capital.

Nesse tipo de empresa, a família, os sujeitos são vistos como máquinas, ou seja, indivíduos que criam habilidades para criar e manter um determinado capital, como é o caso da imagem - um casal que busca a acumulação de um determinado capital, para que essa fábrica (o casal) não sofra com consequências advindas da ausência de uma administração competente.

De acordo com Gadelha (2013, p.148), "a economia política passa a ter como objeto o comportamento humano, ou melhor, a racionalidade interna que o anima". O trabalho, ou conduta, produz um mecanismo que favorece a otimização do indivíduo, atuando como catalisador de suas habilidades.

Desse modo, observamos indícios de que o sujeito é "ele próprio seu capital, sendo para si mesmo o seu produtor, sendo para si mesmo a fonte de sua renda" (FOUCAULT, 2008a, p.311). Esse sujeito não preza a troca, mas a produção a partir de suas próprias práticas, como um sujeito útil em sua vida econômica, ou seja, o sujeito que se faz a partir de suas decisões, seja de investimento, compra, entre outras práticas econômicas.

Esses processos de subjetivação acontecem por estarem em consonância com a forma de governo neoliberal, em que "o estado não pode ser dissociado do conjunto de práticas que fizeram efetivamente que ele se tornasse uma maneira de governar, uma maneira de agir, uma maneira também de se relacionar com o governo" (FOUCAULT, 2008b, p.369), isto é, uma maneira regida por práticas econômicas de controle, de forma muito sutil, em que toda sociedade deve reger como o sistema se rege.

Essas inferências corroboram para considerarmos a família como uma empresa, os sujeitos como máquinas, que precisam gerar capital por meio de suas competências, habilidades e aptidões, produzindo subjetividades que, em

[...] um indivíduo qualquer constituem, elas mesmas, pelo menos virtualmente e relativamente independente da classe social a que ele pertence, seu capital; mais do que isso, é esse mesmo indivíduo que se vê induzido, sob essa lógica, a tomar a si mesmo como um capital, a entreter consigo (e com os outros) uma relação na qual ele se reconhece (e aos outros) como uma microempresa. (GADELHA, 2013, p. 149).

Segundo Foucault (2008a, p. 312), as competências, habilidades e aptidões, algumas delas consideradas hereditárias, seriam elementos inatos. Para os neoliberais, o sujeito nasce e adquire competências, habilidades e aptidões, independentemente das origens e classe social.

Nesse contexto, o sujeito é responsável por seu sucesso, por seu equilíbrio financeiro e por sua produtividade, por meio de suas competências e habilidades. Cabe à matemática financeira, presente nos livros didáticos de matemática do Ensino Médio, instruir sobre as práticas econômicas de mercado, além de compactuar com a forma de governo neoliberal e subjetivar o autogoverno de si mesmo, que o 
neoliberalismo exige, conforme menciona Foucault (2008b, p. 127): "a arte de governar é, precisamente, a arte de exercer o poder na forma e segundo o modelo da economia".

Mas esse modelo de economia busca subjetivar a acumulação de capital para criação de capital; o indivíduo que atua é, ele mesmo, o "capital humano", por meio de suas decisões e produtividade em consequência das mesmas. Esse "capital humano", segundo Foucault (2008a, p. 310), "[...] não é uma concepção da força de trabalho, é uma concepção do capital-competência, que recebe, em função de várias diversas, certa renda que é um salário, uma renda-salário, de sorte que é o próprio trabalhador que aparece como uma espécie de empresa para si mesmo". Trata-se, na verdade, do que Gadelha (2013, p. 149) denomina de "indivíduo-microempresa: Você S/A". A Figura 2 ilustra, com a imagem e o texto, o que escrevemos sobre a ideia da criação de capital humano.

Figura 2 - Modos de representação de Famílias nos livros didáticos

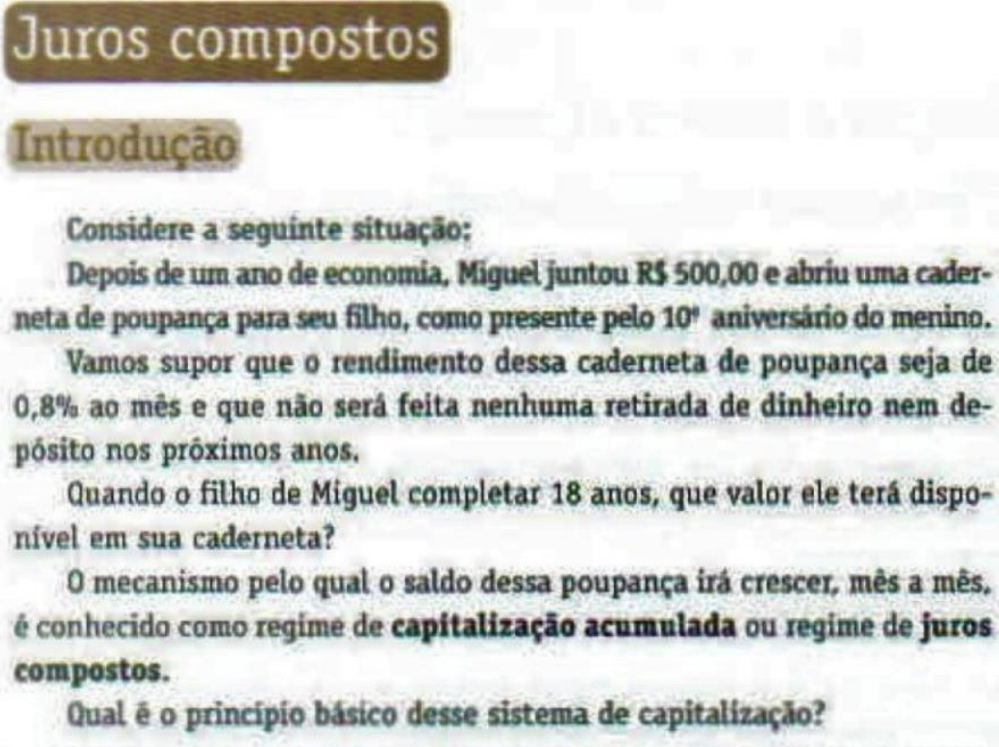
neta de poupança para seu filtho, como presente pelo $10^{\circ}$ aniversairio do menino.

Vamos supor que o rendimento dessa caderneta de poupança seja de $0,8 \%$ ao mès e que não será feita nenhuma retirada de dinheiro nem depósito nos próximos anos.

Quando o filho de Miguel completar 18 anos, que valor ele terá disponivel em sua caderneta?

0 mecanismo pelo qual o saldo dessa poupança irá crescer, mês a mês. é conhecido como regime de capitalização acumulada ou regime de juros compostos.

Qual ê o principío básico desse sistema de capitalizaçào?

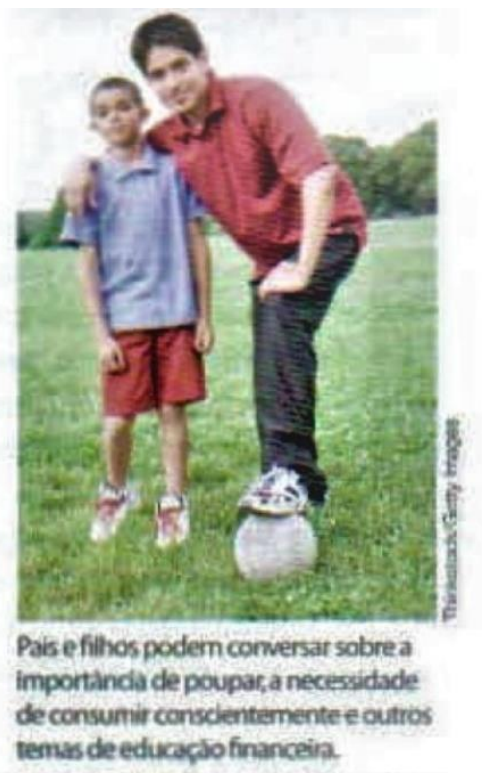

Fonte: lezzi et. al (2013, v. 3, p. 58)

A Figura 2 apresenta uma situação em que um pai abre uma caderneta de poupança para o filho. Ao lado do texto, uma imagem representativa de pai e filho, acompanhada da legenda que sugere que "pais e filhos podem conversar sobre a importância de poupar, a necessidade de consumir conscientemente e outros temas da educação financeira". No texto ao lado da imagem é mencionado o regime de capitalização de juros composto, como um regime acumulativo de mês a mês.

Os significados suscitados pela imagem se associam à formação de um sujeito que se torne responsável por seu empreendimento e sucesso financeiro.

Além disso, a imagem também remete a um aspecto que identificamos na conclusão de Oliveira (2009, p. 181), em que ao problematizar as pedagogias financeiras, concluiu que a 
masculinidade está vinculada à "ótica da previsão, posicionando-o (o elemento masculino) como um investidor" (grifo nosso). Dessa forma, ao analisar essa imagem na qual o pai, homem, instrui o filho, também homem, e o presenteia com uma caderneta de poupança, encontramos semelhança com as conclusões dessa autora, na medida em que o gênero masculino tem sido associado às práticas de investimento, reforçando a ideia de que as práticas voltadas à economia e finanças são mais comuns aos homens.

A Figura 2 também sugere e reafirma, mais uma vez, o padrão de família tradicional, em que a figura masculina está ligada às reponsabilidades relacionadas a empreendimentos. De acordo com Foucault (2008a), essa também é uma relação não-mercantil, mas que se mostra estritamente atrelada às relações econômicas, levando-se em consideração que quando o pai se dedica a instruir o filho ele parece querer manter o capital humano, parece estar transmitindo um capital humano.

Foucault também considera que, quando os pais dedicam mais tempo a instruir seus filhos, a tendência é que estes se tornem sujeitos mais adaptáveis, maiores geradores de capital, de renda, geradores de um capital humano, tendo em vista que "[...] pais cultos vão formar um capital humano, para a criança, muito elevado do que se não tiverem o mesmo nível de cultura -, o conjunto dos estímulos culturais recebidos por uma criança: tudo isso vai constituir elementos capazes de formar um capital humano" (2008a, p. 316).

Nesse caminho, relacionamos a imagem à afirmação de Foucault (2008a), de que os pais passam para os filhos a ideia de que é necessário produzir capital humano e, consequentemente, ser mais produtivo, produzir fluxos de salários, o que pode gerar sujeitos empreendedores. Esse fato se vincula ao que anteriormente já foi abordado em relação ao modelo de família ocidental moderna como exemplo de família tradicional.

As problematizações que discutimos até aqui nos fizeram caminhar em direção à noção de Homo oeconomicus, que surge nas análises que Foucault fez sobre o liberalismo, em que evidencia o homem da troca, o homem que atua no livre comércio. No neoliberalismo essa noção sofreu uma inflexão: os trabalhadores disciplinados são convocados a darem lugar aos empresários de si, tal como expõem Foucault (2008a, p. 311):

[...] é um empresário, e um empresário de si mesmo. Essa coisa é tão verdadeira que, praticamente, o objeto de todas as análises que fazem os neoliberais será substituir, a cada instante, o homo oeconomicus parceiro da troca por um homo oeconomicus empresário de si mesmo, sendo ele próprio seu capital, sendo para si mesmo seu produtor, sendo para si mesmo a fonte de [sua] renda.

Recorremos a essa noção, pois observamos que a matemática financeira presente nos livros didáticos analisados tem contribuído para expansão dessa racionalidade, práticas de empreendimento de si, em que o sujeito, por meio de suas decisões, aptidões, habilidades e competências deve ser seu próprio capital e, a partir dele, ser uma empresa de si mesmo. Sendo que essa empresa está atrelada às práticas de investimento, de empreendimento (GADELHA, 2013). 
O que estamos buscando expressar é a inflexão já referida, um deslocamento que sai do capital humano e chega ao empresário de si ou empreendedor de si, que incide sobre o sujeito que se adapta às situações nas quais irá se enquadrar nessa condição de ser o empresário de si.

Pudemos verificar, também, que, a matemática financeira vincula suas práticas de acúmulo de capital, da criação do empresário de si às práticas de consumo, tal como se pode perceber na Figura 3 :

Figura 3 - Modos de representação de Famílias nos livros didáticos

No terceiro milênio d.C., em uma sociedade organizada e consumista, as pessoas necessitam cada vez mais otimizar os gastos para obter um equilibrio no orşamento doméstico, Esse equilibrio, embora pessoal ou familiar, em seu conjunto favorece a estabilidade da própria economia do país.

Agora, seu grupo vai elaborar um orçamento domiciliar mensal.

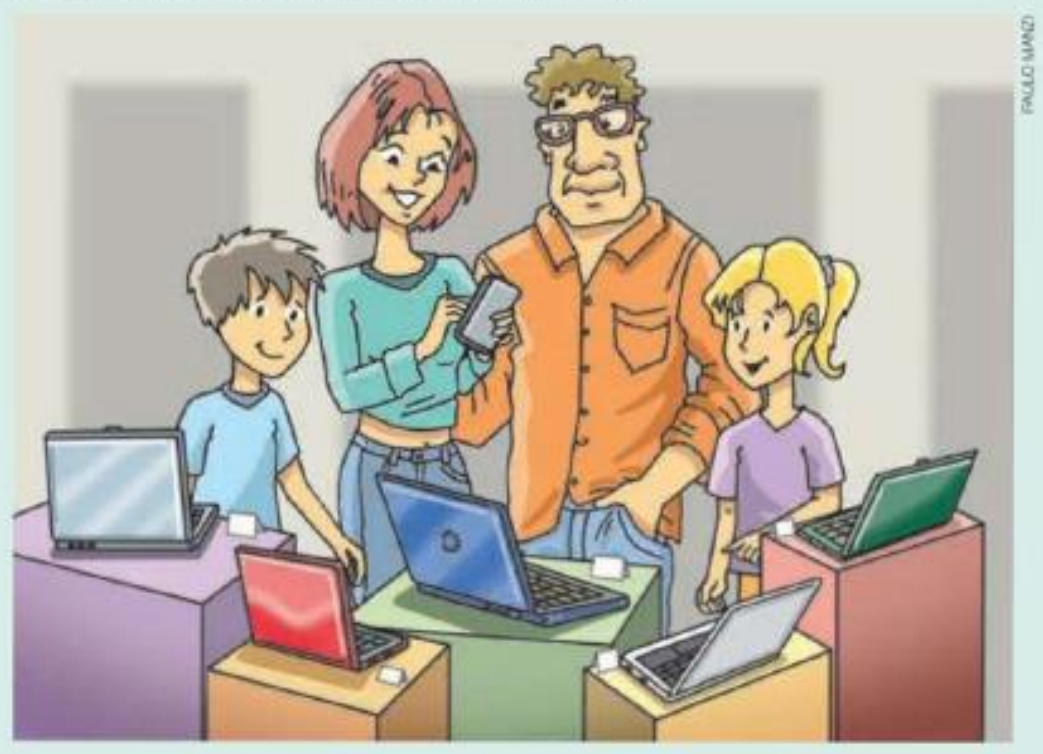

\section{Justificativa}

A preparação laboriosa de um orçamento, com a ajuda da Matemática, contribui para a organizaçào pessoal, para o exercicio da cidadania e para a inclusão social.

Fonte: Paiva (2013, v. 1, p. 62)

A Figura 3 corrobora com a concepção de família tradicional normalizada como uma instância inserida em uma sociedade organizada e consumista. Organizada pelo sistema neoliberal que busca representações de uma família empreendedora e que investe o seu próprio capital humano; consumista, para manter esse sistema, pois quando a economia do país está ligada a um sistema neoliberal, as relações sociais, políticas e econômicas são mediadas pelo consumo, tornam-se totalmente reféns do mercado e incapazes de se sustentarem fora dessa dinâmica, uma vez que o estado não está desvinculado das práticas que constituíram a sua maneira de governar, conforme menciona Foucault (2008b). 
Nesse sentido, para contribuir com a economia de estado, os sujeitos devem ser normalizados, devem ser instruídos a otimizar seus gastos e, desse modo, manter um equilíbrio doméstico. Notemos que, para justificar propostas como essas, foi mencionada a contribuição para o exercício da cidadania.

A partir dessas afirmações, buscamos pensar de "outros modos", pois o termo cidadania não possui um sentido único. Assim, dependendo do contexto social, da cultura, do tipo de representação, compreende-se cidadania de forma diferente. Então, seria uma cidadania baseada na responsabilidade de gerar a economia de estado? De gerar a economia pessoal? Que tipo de cidadania os livros didáticos de matemática, a matemática financeira e o currículo de matemática têm buscado instruir?

Convém ressaltar que o conceito de cidadania foi criado pelos antigos gregos, a fim de evidenciar os indivíduos que habitavam a mesma pólis, ou seja, o cidadão (GALLO; ASPIS, 2010). A cidadania significava que um indivíduo pertencia a uma comunidade. Entretanto, não eram todos os que moravam em uma cidade que eram os cidadãos, e sim aqueles que tinham determinadas condições.

\begin{abstract}
Portanto, a cidadania não está destinada a todos, mas apenas àqueles que possuem meios suficientes para uma vida livre, independente. Aristóteles argumenta que esses meios são a terra para produzir, a casa para habitar, os animais e os escravos como instrumentos de produção. Logo, os cidadãos são os portadores de certas riquezas. São eles que possuem a fala e convivem em liberdade. Daí que, para os gregos, eram duas as características básicas da cidadania: a isegoria, isto é, o direito à palavra pública; e a isonomia, ou o direito de viver sob as mesmas leis. (GALLO; ASPIS, 2010, p. 91).
\end{abstract}

É possível perceber que a cidadania está ligada à forma de "vida livre, independente". Em um modo de vida neoliberal, a cidadania é tratada com foco no mercado, ou seja, ser cidadão é, acima de tudo, ser consumidor. Esse cidadão do consumo busca "maximizar a competição para produzir liberdade e que todos possam estar no jogo econômico. Dessa maneira, o neoliberalismo constantemente produz e consome liberdade. Isso equivale dizer que a própria liberdade transforma-se em mais um objeto de consumo" (VEIGA-NETO, 2013, p. 39).

Assim, as ideias apresentadas indicam a liberdade como um objeto de consumo. Trata-se de um jogo econômico, no qual o currículo de matemática se vincula à sociedade centrada no consumo, para produzir cidadãos livres. Apesar de um disciplinamento para o consumo, só é possível governar corpos livres (FOUCAULT, 2014), uma liberdade vigiada, induzida, produzida em composição com um novo diagrama de forças, buscando capturar vontades, fazendo com que alunos e professores se constituam para um determinado meio social - um meio educado - a fim de se tornarem 'portadores de certas riquezas', ressonâncias de outro lugar histórico, mas que é desse tempo.

Pois bem, o discurso neoliberal, quando atravessa o currículo de matemática, produz liberdades para um mundo do consumo, para capturar a atenção de alunos e professores, como sujeitos de uma peça importante no processo de produção e consumo neoliberal, tramas discursivas que regem para estabelecer sujeitos livres - livres de si mesmos e presos em uma rede de consumo. Porém, felizes! É o que se pode ver na imagem a seguir: 
Figura 4 - Modos de representação de Famílias nos livros didáticos

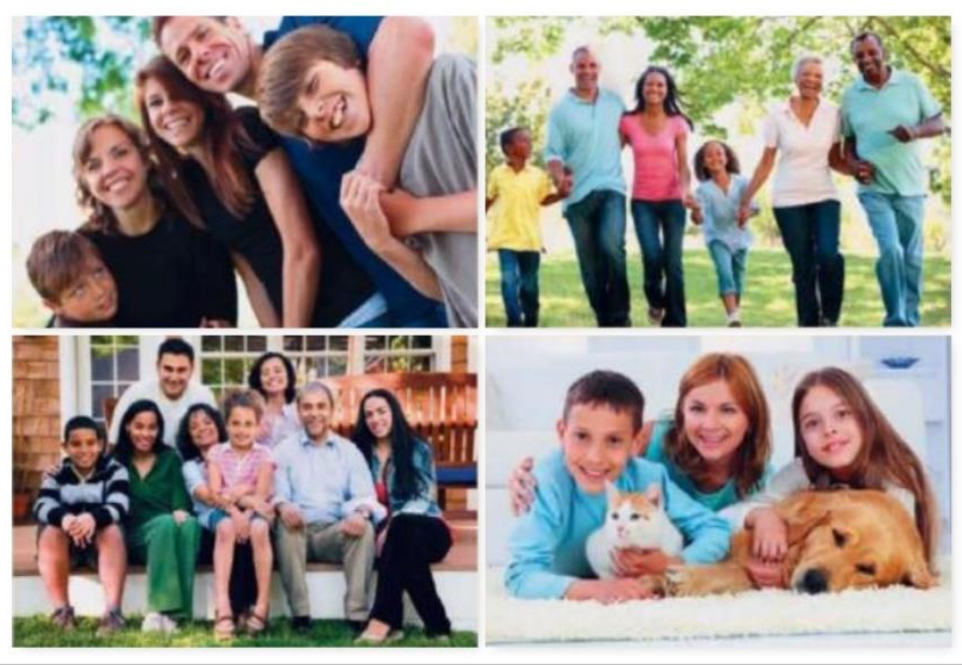

Fonte: Leonardo (2013, v. 3, p.23).

Na Figura 4 observamos a representação de famílias felizes, presentes nos livros didáticos analisados neste trabalho, mas presas às relações econômicas socioeducativas, uma vez que, inseridas nesse jogo competitivo do falso e verdadeiro, o papel da escola e do currículo de matemática busca compactuar com as políticas neoliberais para produzir sujeitos normalizados e manter uma política de desenvolvimento econômico.

De acordo com Abreu (2015, p. 47), essa competição potencializada pelo neoliberalismo faz com que o sujeito se sinta representado por vários papéis, o de "produtor, consumidor, empreendedor, investidor, mercadoria (que se deixa consumir), administrando a si próprio na busca pela sobrevivência no mercado sendo sempre responsabilizado pelas suas ações e escolhas".

Tendo a liberdade para essas escolhas, sempre pautada na competição, o estado oferece condições para que ela seja exercitada, pois, como afirma Gadelha (2013), esses fatos fazem com que esse sujeito da modernidade seja o modelo "econômico empresarial".

As problematizações observadas nos conduziram a discursos, em que sujeitos representados pelas famílias felizes são os empresários de si, quais sejam, aqueles que "são proativos, inovadores, investidores, flexíveis, com senso de oportunidade, com notável capacidade de provocar mudanças etc." (GADELHA, 2013, p. 156), os cidadãos livres neoliberais.

Dessa forma, com base na análise a que procedemos, os livros didáticos de matemática do Ensino Médio aprovados no PNLD de 2015 constituem um tipo de instrução voltada a essa sujeição, voltada à formação de um sujeito que compactua com a forma de governo neoliberal, antes de tudo, um sujeito que seja moldado para entrar na ordem desses discursos, para se ajustar à sua situação econômica e, por si só, buscar empreender-se, utilizar suas competências e habilidades. Desse modo, ele será um sujeito responsável, livre, será cidadão. 


\section{CONSIDERAÇÕES FINAIS}

As coletâneas de livros utilizadas para este estudo foram ofertadas para todas as escolas públicas brasileiras, o que significa dizer que alcançou uma grande parcela dos estudantes brasileiros. Desse modo, a partir da análise realizada, é possível inferir que a matemática financeira atua, de uma forma sutil, a serviço dos modos de governar, dos modos de "ação sobre as ações dos outros, quando as caracterizamos pelo 'governo' dos homens, uns pelos outros - no sentido mais extenso da palavra, incluímos um elemento importante: a liberdade" (FOUCAULT, 1995, p. 244). Trata-se de uma liberdade consumida, construída a partir da cidadania, baseada numa sociedade voltada para o mercado, em que o cidadão é, antes de qualquer coisa, o consumidor. Um sujeito parcialmente livre, mas preso em uma rede de consumo, uma rede que é exercida por uma forma de governo.

Ao observar essas premissas de análise nos livros didáticos, identificamos instruções baseadas em práticas discursivas, em verdades constituídas socialmente, que se materializam no currículo de matemática, contribuindo para sujeitos que terão a capacidade de se dirigir com responsabilidade, empreender-se. Assim, como menciona Veiga-Neto (1999, p. 29), inspirado em Burchel, esse tipo de subjetivação pode "ser descrito como uma nova forma de 'responsabilização', que corresponde às novas formas nas quais os governados são encorajados, livre e racionalmente, a se conduzirem a si mesmos".

Pela análise realizada, concluímos que há regularidades nas representações contidas nesses livros, nas quais percebemos uma relação entre as ideias de "boas" práticas econômicas e "saúde" financeira. O que essas representações sugerem é que, se as instruções contidas nas imagens forem seguidas, uma vida "saudável" será alcançada, perpassando, ainda, a visão de família como uma empresa produtora de capital humano, na qual cada membro constitui-se em um empreendedor de si, responsável pelo sucesso ou fracasso dessa empresa-família. As representações também estão ligadas à ideia de sucesso econômico para obtenção de felicidade. Essas atividades subjetivam alunos, que são educados para se inserirem em uma sociedade governada por políticas neoliberais.

\section{REFERÊNCIAS}

1. ABREU, R. J. R. de. Educação financeira: aspectos discursivos, subjetivação e governamentalidade. 2015. 85 f. Dissertação (Mestrado em Educação) - Universidade São Francisco, Itatiba, 2015.

2. ANDERSON, P. Balanço do neoliberalismo. In: SADER, E.; GENTILI, P. (Orgs.). Pósneoliberalismo: as políticas sociais e o Estado democrático. Rio de Janeiro: Paz e Terra, 1995. p. 923. 
3. ANDRADE, P. D. A invenção das pedagogias culturais. In: CAMOZZATO, V. C.; CARVALHO, R. S.; ANDRADE, P. D. (Org.). Pedagogias culturais: a arte de produzir modos de ser e viver na contemporaneidade. Curitiba: Appris, 2016. p. 19-32.

4. COllange, M.; AlMEIDA, C.; AMORIM, A. C. R. Natureza em imagens de livros didáticos de Biologia do Ensino Médio. Revista de Ensino de Biologia da Associação Brasileira de Ensino de Biologia (SBEnBio), v. 7, p. 826-837, 2014.

5. CORADETTI, C. A. L. M. Um Olhar Contemporâneo para a Matemática Financeira presente nos Livros Didáticos do Ensino Médio. 2017. 126 f. Dissertação (Mestrado em Educação Matemática) Programa de Pós-Graduação em Educação Matemática, Universidade Federal de Mato Grosso do Sul, Campo Grande, 2017.

6. CORADETTI, C. A. L. M.; SILVA, M. A. A Tomada de Decisão: tensionamentos de uma instrução dada pela matemática financeira dos livros didáticos de matemática do ensino médio. Perspectivas da Educação Matemática, Campo Grande, v. 10, n. 22, p. 65-86, 2017.

7. DANTE, L. R. Matemática: contexto e aplicações. 2. ed. São Paulo: Ática, 2013.

8. FIUZA, C. A. C.; POLI, L. C. . Famílias plurais - o direito fundamental à família. Revista da Faculdade de Direito da Universidade Federal de Minas Gerais, v. 67, p. 151-180, 2015.

9. FOUCAULT, M. O sujeito e o poder. In: DREYFUS, H.; RABINOW, P. Michel Foucault: Uma trajetória filosófica - Para além do estruturalismo e da hermenêutica. Rio de Janeiro: Forense universitária, 1995. p. 231-249.

10. .O cuidado com a verdade. In: FOUCAULT, M. Ditos \& Escritos V: Ética, sexualidade, política. 2. ed. Rio de Janeiro: Forense Universitária, 2004. p. 240-250.

11. .Nascimento da Biopolítica: Curso dado no Còllege de France (1978-1979). Tradução de Eduardo Brandão. São Paulo: Martins Fontes, 2008a.

12. Segurança, Território, População: Curso dado no Collège de France (1977-1978). Tradução de Eduardo Brandão. São Paulo: Martins Fontes, $2008 b$.

13. Microfísica do Poder. 18. ed. Rio de Janeiro: Graal, 2014.

14. GADELHA, S. Biopolítica, governamentalidade e educação: introdução e conexões, a partir de Michel Foucault. 1. Reimp. Belo Horizonte: Autêntica, 2013. 
15. GALLO, S.; ASPIS, R. L. Ensino de filosofia e cidadania nas "sociedades de controle": resistência e linhas de fuga. Pro-Posições, Campinas, v. 21, p. 89-105, 2010.

16. GARCÍA CANCLINI, N. Culturas Híbridas: estratégias para entrar e sair da modernidade. Tradução Heloísa Pezza Cintrão; Ana Regina Lessa. 4. ed. São Paulo: Editora da Universidade de São Paulo, 2008. (Ensaios Latino-americanos).

17. HALL, S. Cultura e representação. Rio de Janeiro: Ed. PUC - Rio: Apicuri, 2016. HÖFLING, E. M.. Estado e políticas (públicas) sociais. Cadernos CEDES (UNICAMP), Campinas, v. 21, n.20, p. 3041, 2001.

18. IEZZI, G. et al. Matemática: ciência e aplicações. 7. ed. São Paulo: Saraiva, 2010. LARROSA, J. Tecnologias do eu e educação. In: SILVA, T. T. (Org.). O sujeito da educação: estudos foucaultianos. 5. ed. Petrópolis: Vozes, 2011. p. 35-86.

19. LEONARDO, F. M. de. Conexões com a Matemática. 2. ed. São Paulo: Moderna, 2013. v. 3.

20. LOPES, A. C.; MACEDO, E. Teorias de Currículo. São Paulo: Cortez, 2011.

21. MONTEIRO, A.; MENDES, J. R.; MASCIA, M. A. A. Tramas discursivas em práticas escolares de alfabetização. Zetetiké, Campinas, v. 18, p. 49-68, 2010.

22. OLIVEIRA, H. D. L. de. Entre mesadas, cofres e práticas matemáticas escolares: A constituição de Pedagogias Financeiras para Infância. 2009. 238 f. Tese (Doutorado em Educação) - Universidade Federal do Rio Grande do Sul, Porto Alegre, 2009.

23. PAIVA, M. Matemática. 2. ed. São Paulo: Moderna, 2013.

24. POPKEWITZ, T. S. The Alchemy of the Mathematics Curriculum: Inscriptions and the Fabrication of the Child. American Educational Research Journal, v. 41, n. 1, p. 3-34, 2004.

25. SILVA, M. A. Investigações Envolvendo Livros Didáticos de Matemática do Ensino Médio: a trajetória de um grupo de pesquisa. JIEEM - Jornal Internacional de Estudos em Educação Matemática, São Paulo, v. 9, n. 3, p. 36-54, 2016.

26. SILVA, M. A. Práticas sociais híbridas: contribuições para os estudos curriculares em Educação Matemática. Horizontes, Itatiba, v. 30, n. 2, p. 95-102, 2012.

27. SILVA, M. A.; MIARKA, R. Geni. Pesquisa em [E]educação [M]matemática e o Zepelim. Perspectivas da Educação Matemática, Campo Grande, v. 10, n. 24, p. 752-767, 2017. 
28. SILVA. T. T. Documentos de identidade: uma introdução às teorias do currículo. Belo Horizonte: Autêntica, 2015.

29. SMOLE, K. S.; DINIZ, M. I. Matemática: Ensino Médio. 8. ed. São Paulo: Saraiva, 2013.

30. SOUZA, J. R. de. Novo olhar matemática. 2. ed. São Paulo: FTD, 2013.

31. TRÖHLER, D.; POPKEWITZ, T. S.; LABAREE, D. F. Schooling and the making of citizens in the long nineteenth century: comparative visions. New York: Routledge, 2011. (Routledge resarch in education).

32. VALERO, P. Mathematics for All, Economic Growth, and the Making of the Citizen-Worker. In: POPKEWITZ, T.; DIAZ, J.; KIRCHGASLER, C. (Org.). A political sociology of educational knowledge: Studies of exclusions and difference. New York and London: Routledge, 2017. p. 117132.

\section{Camila Aparecida Lopes Coradetti Manoel}

Doutoranda do Programa de Pós-Graduação em Educação Matemática da Universidade Federal de Mato Grosso do Sul (UFMS), Campo Grande, MS, Brasil.

\section{Marcio Antonio da Silva}

Doutor em Educação Matemática pela Pontifícia Universidade Católica de São Paulo (PUC/SP).

Professor do Instituto de Matemática e do Programa de Pós-Graduação em Educação Matemática da Universidade Federal de Mato Grosso do Sul (UFMS).

\section{Como citar este documento:}

CORADETTI MANOEL, Camila Aparecida Lopes; SILVA, Marcio Antonio da. Famílias felizes e saudáveis! Livros didáticos de matemática e a produção de sujeitos. Reflexão e Ação, Santa Cruz do Sul, v. 27, n. 2, abr. 2019. ISSN 1982-9949. Disponível em: $<$ https://online.unisc.br/seer/index.php/reflex/article/view/11740>. Acesso em: doi:https://doi.org/10.17058/rea.v27i2.11740. 